\title{
ACCURACY ASSESSMENT OF LIDAR-DERIVED DIGITAL TERRAIN MODEL (DTM) WITH DIFFERENT SLOPE AND CANOPY COVER IN TROPICAL FOREST REGION
}

\author{
Mohd Radhie Mohd Salleh a,*, Zamri Ismail ${ }^{\text {b }}$, Muhammad Zulkarnain Abdul Rahman a \\ a TropicalMAP RESEARCH GROUP \\ ${ }^{\mathrm{b}}$ Photogrammetry \& Laser Scanning RESEARCH GROUP, Department of Geoinformation, Faculty of Geoinformation and Real \\ Estate, Universiti Teknologi Malaysia, 81310 UTM Johor Bahru, Johor, Malaysia. \\ *Corresponding author e-mail: mohdradhie.gis@gmail.com
}

KEY WORDS: Airborne LiDAR, Accuracy, Vegetation, Slope, Tropical Forest

\begin{abstract}
:
Airborne Light Detection and Ranging (LiDAR) technology has been widely used recent years especially in generating high accuracy of Digital Terrain Model (DTM). High density and good quality of airborne LiDAR data promises a high quality of DTM. This study focussing on the analysing the error associated with the density of vegetation cover (canopy cover) and terrain slope in a LiDAR derived-DTM value in a tropical forest environment in Bentong, State of Pahang, Malaysia. Airborne LiDAR data were collected can be consider as low density captured by Reigl system mounted on an aircraft. The ground filtering procedure use adaptive triangulation irregular network (ATIN) algorithm technique in producing ground points. Next, the ground control points (GCPs) used in generating the reference DTM and these DTM was used for slope classification and the point clouds belong to non-ground are then used in determining the relative percentage of canopy cover. The results show that terrain slope has high correlation for both study area ( 0.993 and 0.870) with the RMSE of the LiDAR-derived DTM. This is similar to canopy cover where high value of correlation (0.989 and 0.924) obtained. This indicates that the accuracy of airborne LiDAR-derived DTM is significantly affected by terrain slope and canopy caver of study area.
\end{abstract}

\section{INTRODUCTION}

Light Detection and Ranging (LiDAR) is an active remote sensing technique that able to map various activities of the Earth's surface and features such as vegetation and building, which also provides Digital Terrain Model (DTM) with up to sub-meter vertical accuracy (Bater, 2009) and increasingly being used to map forested terrain (Reutebuch et al., 2003). It works by determine the distance between the sensors and ground objects by measuring the time of the transmitted pulse return to the LiDAR sensor from the objects or ground surface. Nowadays, airborne LiDAR is one of the technology that widely used in surveying and industrial measurement applications (Cui, 2013). This technology acquire digital elevation data effectively and accurately as compared to conventional methods (Ismail et al., 2015). Furthermore, LiDAR with high resolution data can be used in generating the digital terrain models (DTMs) and digital surface models (DSMs) which is important to support wide range of applications such as specific research, education, management of public resources (Hodgson et al., 2005) engineering projects, hydrology and floodplain management, corridor mapping, etc. (Cui, 2013). By applying suitable processing technique, a high quality of DTM can be generated from LiDAR data (Cui et al., 2013). Hence, an effective of LiDAR data processing is important to all the applications (Axelsson, 1999).

However, the classification of point cloud or LiDAR data filtering process which focusing on the ground and non-ground points separation are very crucial to most of the applications (Cui, 2013). Although, most of the research agree that the RMSE of LiDAR elevation data is $\pm 15 \mathrm{~cm}$ but it is only for the limited area with flat terrain, less vegetation, and low altitude during data collection (Hodgson and Bresnahan, 2004). More studies should be conducted to determine the level of accuracy with various physical environment and also other external factors that will give an impact to the quality of DTM such as land cover type, land forms, etc. Besides that, the classification of LiDAR point clouds that represents as terrain is a fundamental problem in the production of high quality of DTMs (Pingel et al., 2013). The filtering of LiDAR data become more challenging especially at high relief area or hybrid geographic features ( $\mathrm{Li}, 2013$ ). Although dozens of filtering algorithm have been developed in separation of ground points, the difficulties in this extraction still exist where most of the algorithm need specific condition to produce good results (Meng et al., 2010) such as flat and open areas, . Due to this scenario, more studies should be conducted in order to providing the understanding of the limitations of DTM accuracy relative to various intended end uses, and also may provide direction in improving the DTM development ( $\mathrm{Su}$ and Bork, 2006)

Many studies on the capability of airborne LiDAR system in producing DTM have been done in developed or temperate countries but still demanded in tropical area especially in Malaysia (Ismail et al., 2015). Terrain slope and land cover type become emerging factor in contributing the error to the LiDARderived DTM (Goncalves et al., 2006; Hodgson and Bresnahan, 2004; Raber et al., 2002; Su and Bork, 2006). An area with highly dense canopy facing difficulties for airborne LiDAR signal to penetrate and reach to the ground. This may lead to the density of ground point is lower than open space area. This situation contribute significantly to the error of DTM generated. In term of slope effects, Figure 1 shows the illustration on how terrain slope effect the LiDAR data. 


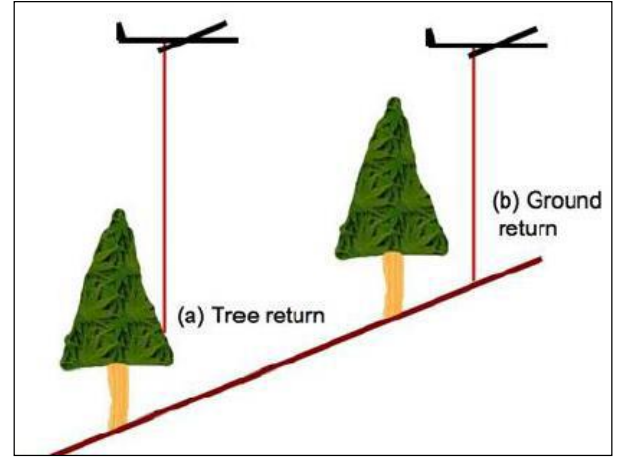

Figure 1. The illustration for impact of slope towards the accuracy of LiDAR data (Lewis and Hancock, 2007).

Based on the Figure 1, although sample (a) as tree return such as from tree crown, branches, etc. but the terrain slope causing the classification of sample (a) as ground points because sample (b) as ground return is at a higher altitude (Lewis and Hancock, 2007). This situation is challenging in filtering the LiDAR data for major filtering algorithms. Besides that, horizontal error may introduce "apparent" error in the elevation value where any 100 $\mathrm{cm}$ horizontal error on a $10^{0}$ slope can be up to $18 \mathrm{~cm}$ of elevation error (Hodgson and Bresnahan, 2004). In addition, high density of vegetation also reduce the number of LiDAR ground points due to less signal can penetrate the canopy and reach to the ground along with the slope affects the generation of highly accurate DTM.

\section{STUDY AREA AND DATA}

\subsection{Description of the data and study area}

In this study, two study area are chosen where located in the south-west of Bentong District, State of Pahang, Malaysia (see Figure 2 (a) and (b)). The first study area is mainly covered by rubber trees while the next study area covered with mixed forest. Both of these two study areas can be considered as tropical forest area where they covered by high canopy density and undulating terrain. The slope gradient range between $0^{0}$ and $15^{\circ}$ and the canopy density more than 60 percent $(\%)$. The sample of photos taken over study areas as shown in the Figure 3 (a),(b), and (c).

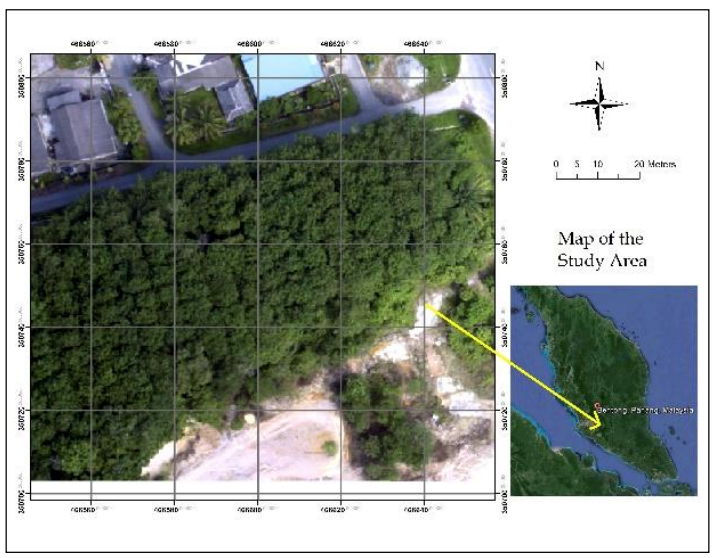

(a)

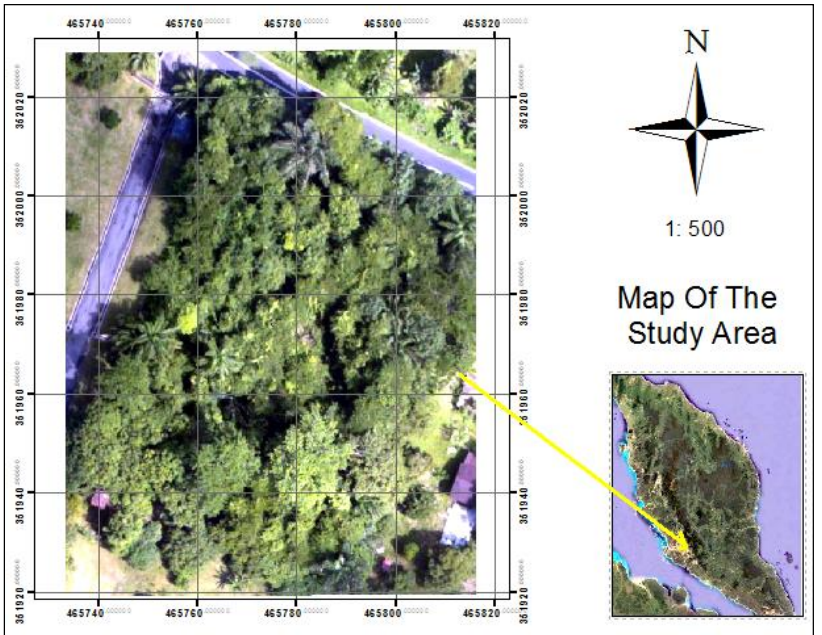

(b)

Figure 2. Map of study area covered with (a) rubber trees vegetation; (b) mixed forest.

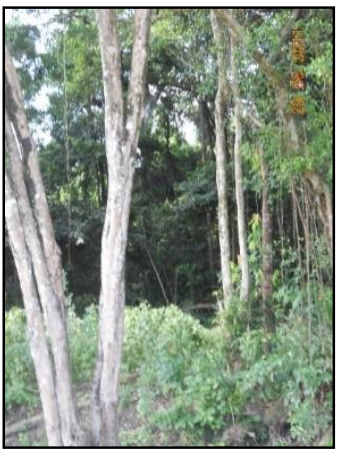

(a)

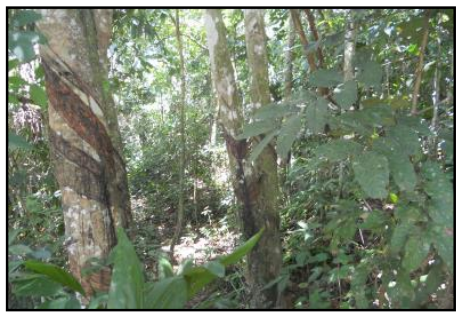

(b)

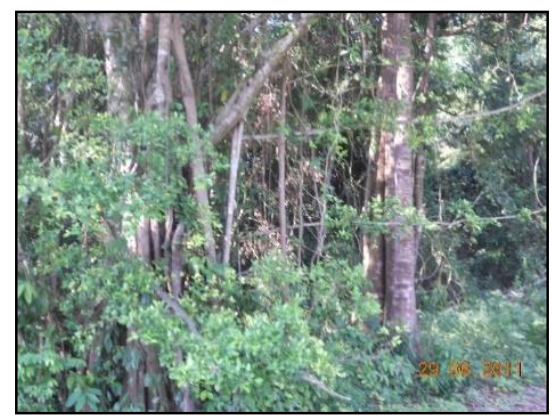

(c)

Figure 3. Photographs taken over study area covered with rubber trees (a) and (b) with understorey vegetation (c) mixed forest

Airborne LiDAR data (Figure 4 and Figure 5) were collected by survey firm company on January 2009 using REIGL laser scanner which is mounted on a British Nomad aircraft. The data were delivered in LAS format and the average point density is about 1.3 points per meter square (rubber trees) and 3.2 points per meter square (mixed forest). The airborne LiDAR data were processed using an automated methods in classifying ground returns and using manual interpretation. This process known as 
ground filtering that further discussed in airborne LiDAR filtering section.

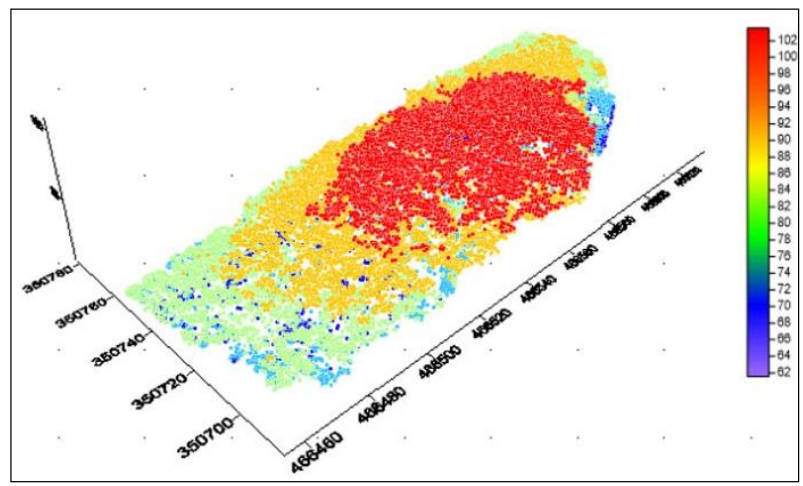

Figure 4. Raw airborne LiDAR data for rubber trees vegetation

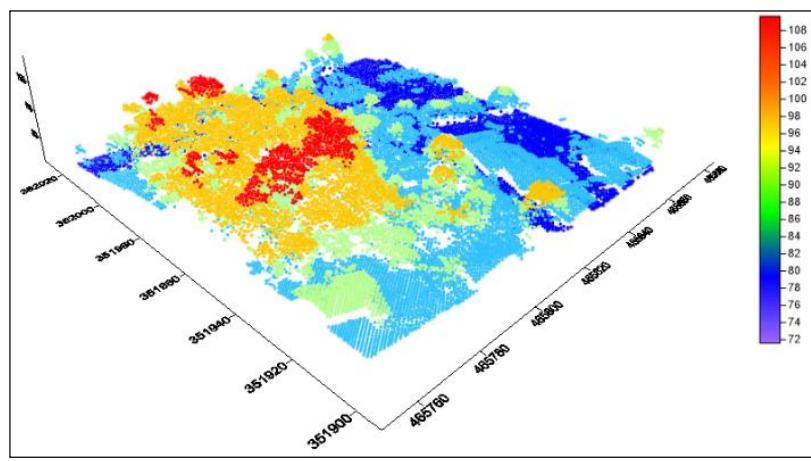

Figure 5. Raw airborne LiDAR data for mixed forest vegetation

In order to perform validation or assessment for DTM generated, several Ground Control Points (GCPs) used for that purpose. Slope map also generated from these field collected data and it is collected by carried out ground survey technique by using Nikon Total Station with an optical levelling capability. The total number of GCPs collected for rubber trees area and mixed forest areas is 126 points and 69 points are respectively. Field crews visited the study area and characterised the land cover type of the study area. Most of the GCPs collected were under forested canopy and slope area. This is important in order to investigate the effect of tropical forest characteristics towards the accuracy of LiDAR-derived DTM.

\section{METHODOLOGY}

As mentioned in the introduction, airborne LiDAR data is commonly used in generating the DTMs. However, the environmental factor especially for tropical forest area introduce an error to the DTM generated. Hence, this study focusing on the investigating the factor of slope and canopy cover towards the accuracy of LiDAR-derived DTM. The process include four parts:

\footnotetext{
i. Airborne LiDAR filtering.

ii. DTM generation.

iii. Slope and canopy cover classification.

iv. Accuracy assessment.
}

\subsection{Airborne LiDAR filtering}

Airborne LiDAR filtering (also known as ground filtering) is a critical process before implementing it in any applications. Good filtering process give an impact towards the accuracy of DTM. In this study, ground filtering is performed using the adaptive Triangulated Irregular Network (ATIN) densification algorithm. ATIN filter works by employing the distance of point on the surface of a TIN in order to separate the ground points from airborne LiDAR dataset. Basically, four parameters need to be specified for each study area in order to extract ground points as follows:

i. maximum building size,

ii. iteration angle,

iii. terrain angle, and

iv. iteration distance.

Since there is no building in the chosen study area, the maximum building size is set to the $5 \mathrm{~m}$ which is the minimum size of standard building. This filter starts with the generating the initial TIN from seed points where the lowest points in each raster grid. This TIN surface adapts to the points and more ground points are added if they meet the threshold. The threshold is determined from other parameters also (iteration angle, terrain angle, and iteration distance). Iteration angle is the maximum angle of the point clouds and the TIN facets. Iteration distance is used to ensure the iteration does not make big jump upwards when triangle are large. This capability helps in removing any buildings measurement in the dataset.

\subsection{DTM generation}

At this stage, GCPs which collects in the field are interpolated by using Kriging method with $1.0 \mathrm{~m}$ spatial resolution. Kriging is a geostatistical method for point interpolation where the statistical surface as a regionalised variable, with a certain degree of continuity (Caruso and Quarta, 1998). Figure 6 and Figure 7 below shows the DTM generated from GCPs for each study area.

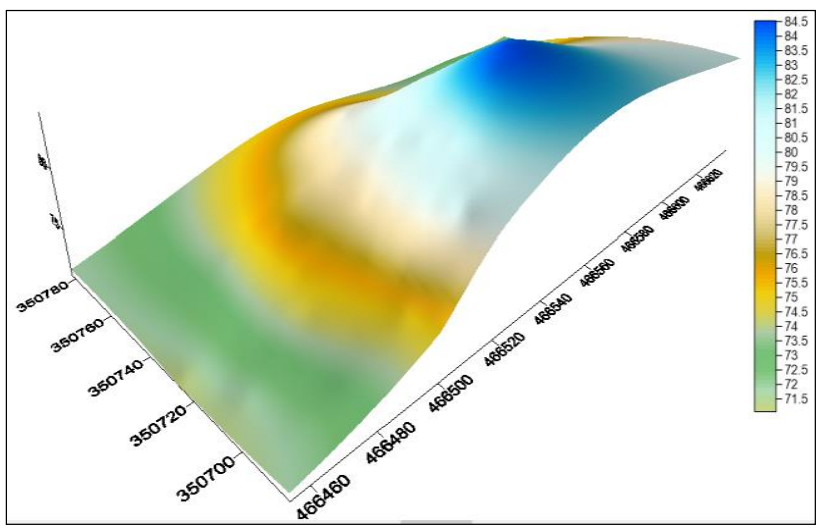

Figure 6. DTM generated from GCPs for rubber trees area 


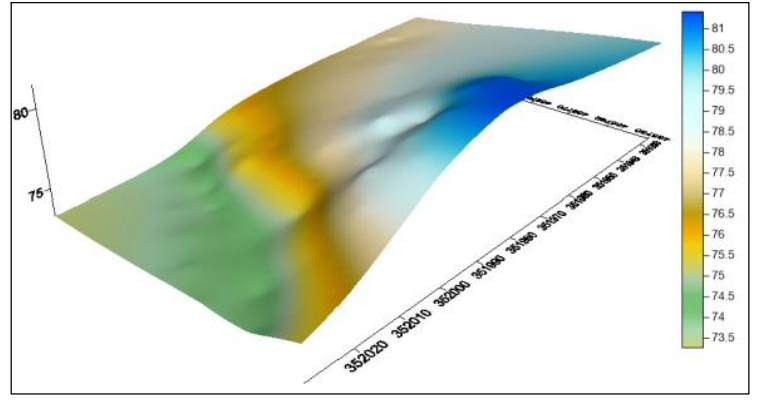

Figure 7. DTM generated from GCPs for mixed forest area

Both of the DTM generated are further used in producing the slope map in order to obtain an accurate of slope map. LiDAR ground points also have been interpolated using Kriging method for DTM generation with $1.0 \mathrm{~m}$ spatial resolution for assessment purpose.

\subsection{Slope and canopy cover classification}

The slope map is generated from DTM of field collected data (Figure 8 (a) and (b)). The slope map is then classified into three classes i.e. class $1\left(0^{0}-5^{0}\right)$, class $2\left(6^{0}-10^{0}\right)$, and class $3\left(11^{0}-\right.$ $\left.15^{\circ}\right)$ as shown in Table 1.

\begin{tabular}{|cc|}
\hline Class & Slope range (Degrees) \\
\hline 1 & $0-5$ \\
2 & $6-10$ \\
3 & $11-15$ \\
\hline
\end{tabular}

Table 1. The slope classification over study area

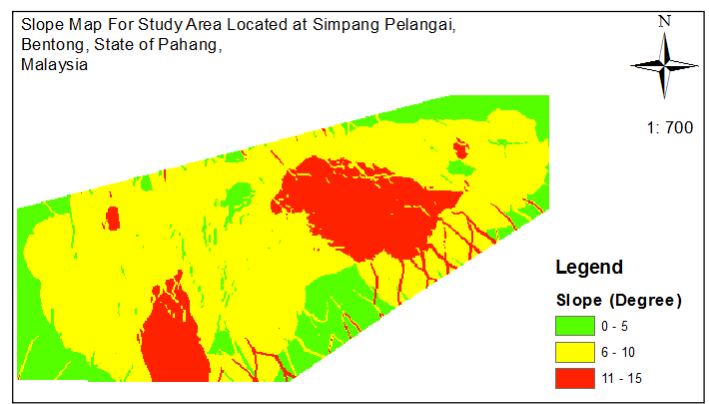

(a)

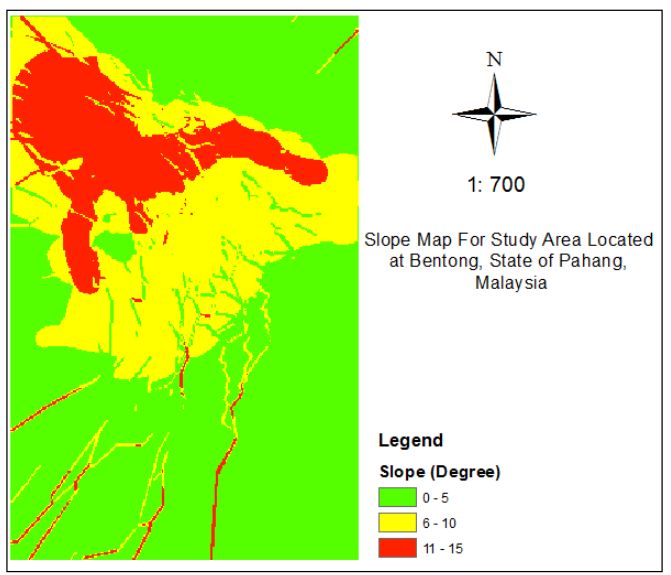

(b)

Figure 8. Slope map for (a) rubber trees area, and (b) mixed forest area.
The canopy cover is calculated based on relatively of non-ground airborne LiDAR data over all LiDAR returns. It is define by dividing the number of non-ground points and the total number of points from airborne LiDAR data over a specific area (1).

Canopy cover $=\frac{\text { Non-ground points }}{\text { Total points }} \times 100$

where Canopy cover is in percent unit of canopy density, nonground points is the laser points classified as non-ground and total points is the total points in a specific area. In this study, $5 \mathrm{~m}$ spatial resolution used in identifying the canopy cover for both study area. The value of $5 \mathrm{~m}$ resolution used because it need to be at least four times the average point spacing. Table 2 shows the classification of canopy density of the study area and Figure 9 (a) and (b) shows these maps.

\begin{tabular}{|cc|}
\hline Class & Canopy Density (\%) \\
\hline 1 & $70-80$ \\
2 & $81-90$ \\
3 & $90-100$ \\
\hline
\end{tabular}

Table 2 . The canopy density classification over study area

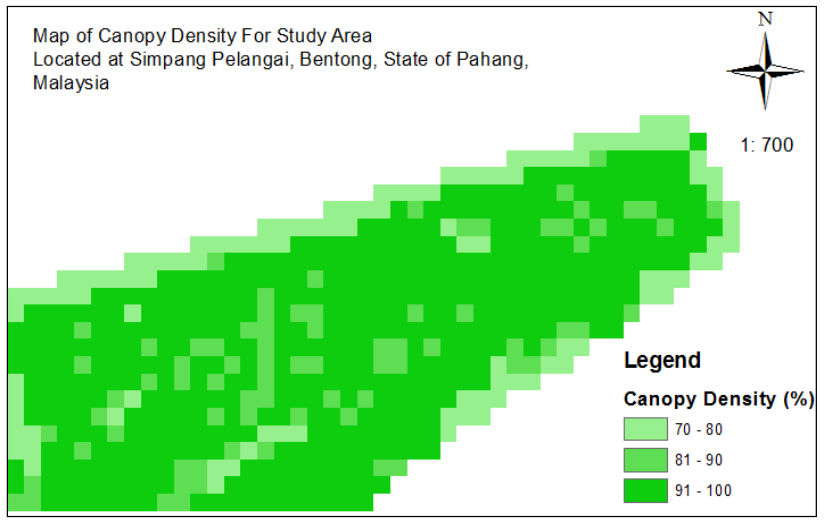

(a)

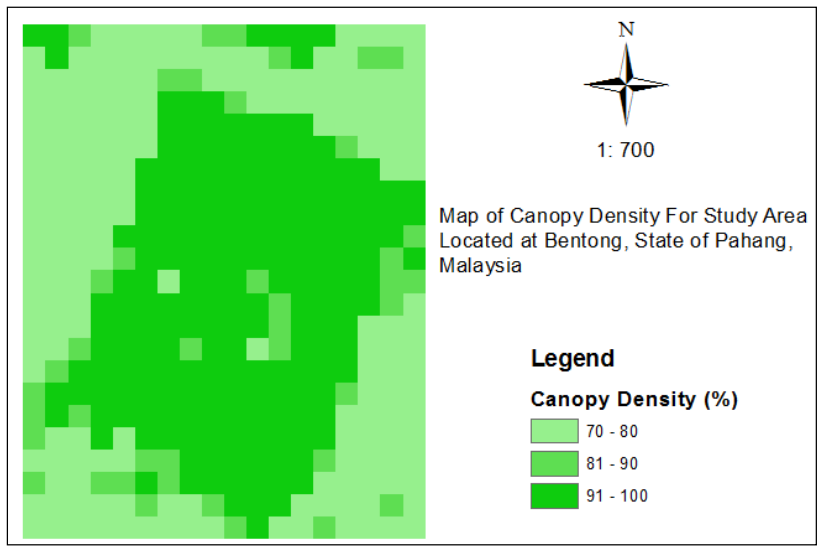

(b)

Figure 9. Canopy density map for (a) rubber trees area, and (b) mixed forest area.

\subsection{Accuracy assessment}

The accuracy assessment step is carried out by comparing the elevation values obtained from the LiDAR-derived DTM with the field collected elevation data. The comparison will be based 
on the value of Root Mean Squared Error (RMSE), Mean Absolute Error (MAE) and Mean Bias Error (MBE) presented in equation (2) to (4).

$$
\begin{aligned}
& R M S E=\sqrt{\frac{\sum_{\mathrm{i}=1}^{\mathrm{n}}\left(\mathrm{Z}_{L i D A R_{\mathrm{i}}}-\mathrm{Z}_{G C P_{i}}\right)^{2}}{\mathrm{n}}} \\
& M A E=\frac{\sum_{i=1}^{\mathrm{n}}\left|\mathrm{Z}_{\text {LiDAR }_{i}}-\mathrm{Z}_{G C P_{i}}\right|}{n} \\
& M B E=\frac{\sum_{i=1}^{n}\left(\mathrm{Z}_{L i D A R_{i}}-Z_{G C P_{i}}\right)}{n}
\end{aligned}
$$

where $n$ is the number of samples, $Z_{L i D A R}$ is the terrain elevation obtained from the LiDAR-derived DTM, $Z_{G C P}$ is terrain elevation value obtained from the field GCP.

\section{RESULTS AND DISCUSSION}

\subsection{The effect of terrain slope on airborne LiDAR-derived DTM}

Based on fundamental research in topographic mapping study, the elevation error would increase as terrain slopes increases (Maling, 1988). Most of previous research also found that the error of LiDAR-derived DTM is highly contributed by terrain slope (Hodgson and Bresnahan, 2004; Hodgson et al., 2003; Spaete et al., 2011). Table 3 ( $a$ and b) and Figure 10 ( $a$ and b) shows the error of LiDAR-derived DTM associated with terrain slope in this study.

\begin{tabular}{|cccc|}
\hline Slope Degree & RMSE $(\mathrm{m})$ & MAE $(\mathrm{m})$ & MBE $(\mathrm{m})$ \\
\hline $0-5$ (Class 1) & 0.613 & 0.364 & 0.020 \\
$6-10$ (Class 2) & 0.723 & 0.410 & 0.002 \\
$11-15$ (Class 3) & 0.890 & 0.619 & 0.017 \\
\hline
\end{tabular}

(a)

\begin{tabular}{|cccc|}
\hline Slope Degree & RMSE $(\mathrm{m})$ & MAE $(\mathrm{m})$ & MBE $(\mathrm{m})$ \\
\hline $0-5$ (Class 1) & 0.379 & 0.153 & 0.010 \\
$6-10$ (Class 2) & 0.589 & 0.012 & -0.024 \\
$11-15$ (Class 3) & 0.590 & 0.425 & 0.054 \\
\hline
\end{tabular}

(b)

Table 3. Error of LiDAR-derived DTM associated with terrain slope over (a) rubber trees area, and (b) mixed-forest area

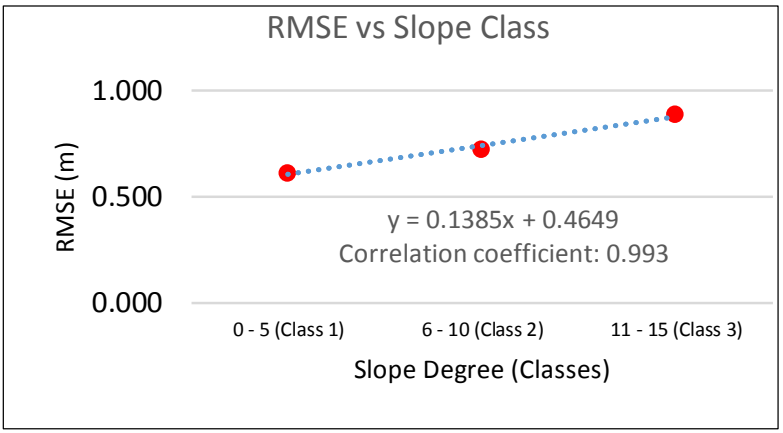

(a)

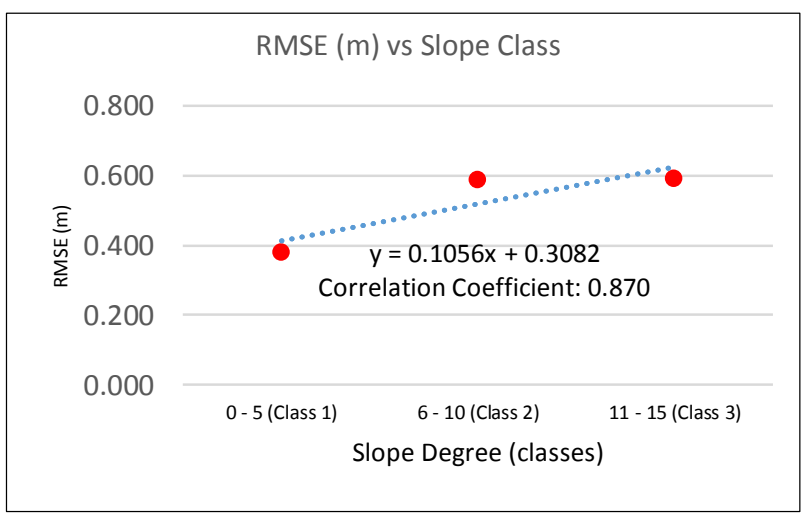

(b)

Figure 10. Graph for error of LiDAR-derived DTM associated with terrain slope over (a) rubber trees area, and (b) mixed-forest area

According to the result obtained, the accuracy of DTM generated is varied with the terrain slope for both study areas. This findings was expected where slope class 3 has recorded a largest error for both study area which are $0.890 \mathrm{~m}$ (rubber trees) and $0.590 \mathrm{~m}$ (mixed forest). The correlation coefficient of this relationship also high for these two study area where 0.993 (rubber trees) and 0.870 (mixed-forest). This indicates the factor of terrain slope is significantly contribute an error to the LiDAR-derived DTM. Most of the slope class shows the positive bias means underestimate exists in DTM generated at high terrain.

\subsection{The effect of canopy cover on airborne LiDAR-derived DTM}

Most of the previous study shows that high density of vegetation area give an impact towards the accuracy of DTM generated from airborne LiDAR data. In this paper, the evaluation of DTM generated from LiDAR data based on the canopy cover is classified into three (3) classes as shown in the Table 4 (a and b) while Figure 11 ( $\mathrm{a}$ and $\mathrm{b}$ ) shows the graph plotting from that result. 


\begin{tabular}{|cccc|}
\hline $\begin{array}{c}\text { Canopy Density } \\
(\%)\end{array}$ & RMSE $(\mathrm{m})$ & MAE $(\mathrm{m})$ & MBE $(\mathrm{m})$ \\
\hline $70-80$ (Class 1) & 0.230 & 0.035 & 0.011 \\
$81-90$ (Class 2) & 0.437 & 0.255 & 0.008 \\
$91-100$ (Class 3) & 0.789 & 0.495 & 0.002 \\
\hline
\end{tabular}

(a)

\begin{tabular}{|cccc|}
\hline $\begin{array}{c}\text { Canopy Density } \\
(\%)\end{array}$ & $\begin{array}{c}\text { RMSE } \\
(\mathrm{m})\end{array}$ & MAE $(\mathrm{m})$ & MBE $(\mathrm{m})$ \\
\hline $70-80$ (Class 1) & 0.333 & 0.333 & 0.162 \\
$81-90$ (Class 2) & 0.367 & 0.179 & 0.075 \\
$91-100$ (Class 3) & 0.576 & 0.076 & 0.019 \\
\hline
\end{tabular}

(b)

Table 4. Error of LiDAR-derived DTM associated with canopy cover over (a) rubber trees area, and (b) mixed-forest area

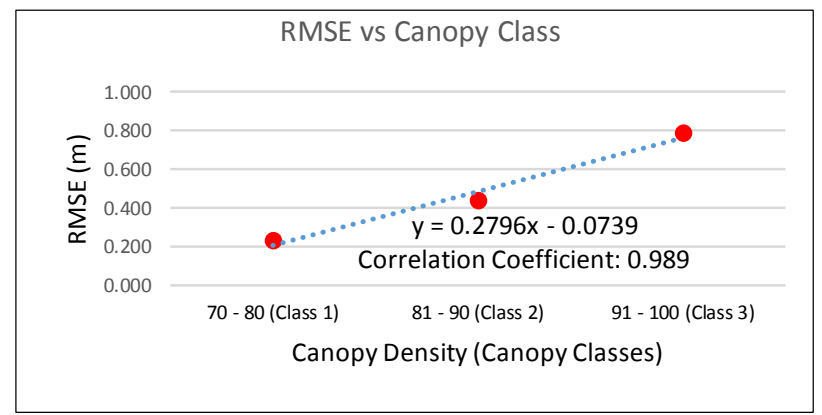

(a)

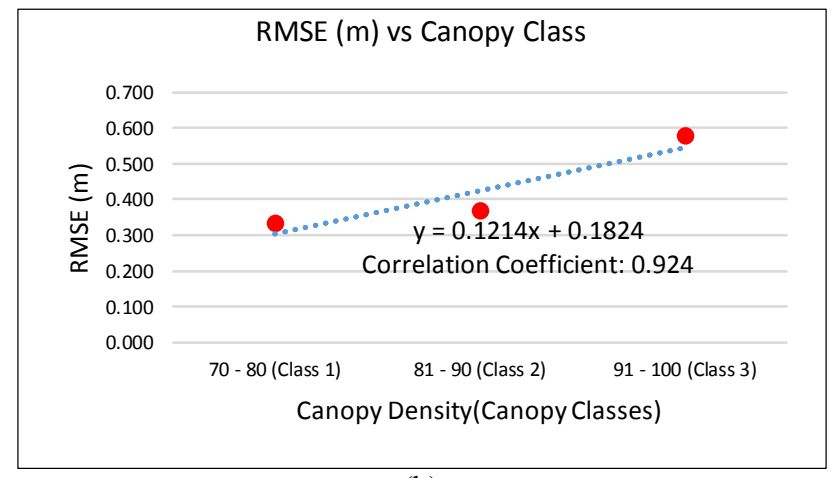

(b)

Figure 11. Graph for error of LiDAR-derived DTM associated with canopy cover over (a) rubber trees area, and (b) mixed-forest area

As previously discussed, the canopy cover is defined relatively by dividing the number of LiDAR non-ground points over total number of LiDAR points at specific area. This clearly shows that the area with high dense of canopy have less number of LiDAR ground points and this situation will probably produce an error to the DTM generated. Based on the result, it was expected where the error of LiDAR-derived DTM increases through high canopy density. Canopy class 3 recorded the highest error for both of study area which are $0.789 \mathrm{~m}$ (rubber trees) and $0.576 \mathrm{~m}$ (mixedforest). The correlation coefficient for both cases also positively correlated with value of 0.989 (rubber trees) and 0,924 (mixed- forest). This indicates the significant effect canopy density towards the accuracy of LiDAR-derived DTM.

\section{CONCLUSIONS AND FUTURE WORK}

This study demonstrates the airborne LiDAR data in generating DTM over tropical forest area. The tropical characteristics such as steep area covered with dense vegetation absolutely produce different accuracy than other land cover (i.e. urban). The results of this study clearly show the variation in error of LiDAR-derived DTM by different slope gradient and canopy cover. Both of study area affected by terrain slope where the RMSE is higher by increasing the slope terrain. The vertical error of LiDAR-derived DTM is typically large and is expected to have this kind of result. This prove that slope have a significant impact on the accuracy of LiDAR-derived DTM in steeper terrain. This is similar to the canopy cover situation where RMSE value also higher at dense canopy. The error would be continuously increasing with combination of steeper terrain and dense canopy area. This study could be further used in identify relationship of many physical environmental factors towards the accuracy of LiDAR-derived DTM.

\section{ACKNOWLEDGEMENTS}

The author would like to staff of the TropicalMAP Research Group and Photogrammetry \& Laser Scanning RESEARCH GROUP who assisted us with the extensive advice and suggestions in carried out this study.

\section{REFERENCES}

Axelsson, P., 1999. Processing of laser scanner data-algorithms and applications. ISPRS Journal of Photogrammetry and Remote Sensing, $\quad 54(2-3), \quad 138-147 . \quad$ doi: http://dx.doi.org/10.1016/S0924-2716(99)00008-8

Bater, Christopher W., \& Coops, Nicholas C., 2009. Evaluating error associated with lidar-derived DEM interpolation. Computers \& Geosciences, 35(2), 289-300. doi: http://dx.doi.org/10.1016/j.cageo.2008.09.001

Caruso, C, \& Quarta, F., 1998. Interpolation methods comparison. Computers \& Mathematics with Applications, $35(12), 109-126$

Cui, Z., 2013. A Generalized Adaptive Mathematical Morphological Filter for LIDAR Data.

Cui, Z., Zhang, Zhang K., Chengcui, Yan, Jianhua, \& Chen, ShuChing., 2013. A GUI based LIDAR data processing system for model generation and mapping. Paper presented at the Proceedings of the 1st ACM SIGSPATIAL International Workshop on MapInteraction, Orlando, Florida.

Gonçalves-Seco, Luis, Miranda, David, Crecente, Rafael, \& Farto, J., 2006. Digital terrain model generation using airborne LiDAR in a forested area Galicia, Spain. Paper presented at the Proceedings of 7th International symposium on spatial accuracy assessment in natural resources and environmental sciences. 
Hodgson, M. E., \& Bresnahan, P., 2004. Accuracy of Airborne Lidar-Derived Elevation. Photogrammetric Engineering \& Remote Sensing, 70(3), 331-339.

Hodgson, M.E., J.R. Jensen, L. Schmidt, S.R. Schill, and B. Davis, 2003. An evaluation of LIDAR-and IFSAR-derived digital elevation models in leaf-on conditions with USGS Level 1 and Level 2 DEMs. Remote Sensing of Environment, 84(2), 295-308.

Hodgson, M.E., J.R. Jensen, G.T. Raber, J.A. Tullis, B.A. Davis, G. Thompson and K., 2005. An evaluation of lidar-derived elevation and terrain slope in leaf-off conditions. Photogrammetric Engineering \& Remote Sensing, 71(7), 817823.

Ismail, Z., Rahman, M. Z. A., Salleh, Salleh, M. R. M., \& Yusof, A. R. M., 2015. Accuracy Assessment of LIDAR-Derived Elevation Value Over Vegetated Terrain in Tropical Region. Jurnal Teknologi, 73(5).

Lewis, P, \& Hancock, S., 2007. LiDAR for vegetation applications. UCL, Gower St, London, UK.

Li, Yong., 2013. Filtering Airborne LiDAR Data by An Improved Morphological Method Based on Multi-gradient Analysis. ISPRS, 191-194.

Maling, Derek H., 1988. Measurements from maps: principles and methods of cartometry: Butterworth-Heinemann.

Meng, X., Currit, N., \& Zhao, K., (2010). Ground Filtering Algorithms for Airborne LiDAR Data: A Review of Critical Issues. Remote Sensing, 833-860.

Pingel, Thomas J., Clarke, Keith C., \& McBride, William A., 2013. An improved simple morphological filter for the terrain classification of airborne LIDAR data. ISPRS Journal of Photogrammetry and Remote Sensing, 77(0), 21-30. doi: http://dx.doi.org/10.1016/j.isprsjprs.2012.12.002

Raber, George T, Jensen, John R, Schill, Steven R, \& Schuckman, Karen, 2002. Creation of digital terrain models using an adaptive lidar vegetation point removal process. Photogrammetric engineering and remote sensing, 68(12), 13071314.

Reutebuch, S. E, McGaughey, R. J., Andersen, Hans-Erik, \& Carson, W. W., 2003. Accuracy of a high-resolution lidar terrain model under a conifer forest canopy. Canadian Journal of Remote Sensing, 29(5), 527-535.

Spaete, Lucas P., Glenn, N.F., Derryberry, D. R, Sankey, Temuulen, T., Mitchell, J. J., \& Hardegree, S. P., 2011. Vegetation and slope effects on accuracy of a LiDAR-derived DEM in the sagebrush steppe. Remote Sensing Letters, 2(4), 317 326.

Su, J., \& Bork, E., 2006. Influence of vegetation, slope, and lidar sampling angle on DEM accuracy. Photogrammetric Engineering $\&$ Remote Sensing, 72(11), 1265-1274. 